\title{
Adaptive Model Reference Sliding Mode Control of Structural Nonlinear Vibration
}

\author{
Luyu Li $\mathbb{D}^{1,2}$ Naibang Wang, ${ }^{3}$ and Han Qin $\mathbb{D i D}^{1,2}$ \\ ${ }^{1}$ State Key Laboratory of Coastal and Offshore Engineering, Dalian University of Technology, Dalian, Liaoning 116024, China \\ ${ }^{2}$ School of Civil Engineering, Dalian University of Technology, Dalian, Liaoning 116024, China \\ ${ }^{3}$ East China Architectural Design \& Research Institute Co., Ltd. Northwest Center, Xi'an, Shanxi 710065, China
}

Correspondence should be addressed to Luyu Li; liluyu@dlut.edu.cn

Received 24 January 2019; Accepted 14 April 2019; Published 28 April 2019

Academic Editor: Angelo Marcelo Tusset

Copyright ( 2019 Luyu Li et al. This is an open access article distributed under the Creative Commons Attribution License, which permits unrestricted use, distribution, and reproduction in any medium, provided the original work is properly cited.

\begin{abstract}
In this paper, an active mass damper (AMD) with adaptive control design is used to mitigate the vibrations of a multi-degree-offreedom (MDOF) nonlinear structure under earthquake excitation. In the adaptive control design, a modified unscented Kalman filter (UKF) is developed to identify the unknown states and parameters adaptively. Based on the identified states and parameters, model reference sliding model control (MRSMC) is proposed for structural nonlinear vibration control. In the design of MRSMC, the structure with tuned mass damper (TMD) is used as a reference model. In the control process, the parameters and states needed to obtain the control forces are updated adaptively through UKF. A numerical example of a three-story shear-type model with an active mass damper (AMD) mounted on the top story is used to study the proposed controller. The interstory shear restoring forces are simulated by the Bouc-Wen model. This model could simulate the hinge effect of the yielding joints in steel structures or the performance of the hysteretic energy dissipation devices. The simulation results demonstrated that, with the help of the modified UKF method and the reference model, the vibration of the structure is effectively mitigated under the proposed MRSMC.
\end{abstract}

\section{Introduction}

Structural control has received much attention in the research community during the last few decades [1-3]. Under strong earthquake excitations, a structure can experience nonlinear deformation that may cause damage or even collapse the structure. In steel structures, large deformation can induce yielding of the structure. In concrete structure, yielding of the structural components can also generate hysteretic forces. New energy dissipation devices, such as steel dampers, friction dampers, shape memory alloy dampers, pounding and impact dampers, and magnetorheological dampers, can also bring nonlinear forces into the structure [4-13]. Therefore, the study of structural vibration control considering the hysteretic effect is of great importance. To model the hysteretic effect, the Bouc-Wen model is widely used in civil engineering due to its ability to simulate various hysteretic behaviors [14-16]. Therefore, the nonlinearity of the structure is simulated using the Bouc-Wen model in this paper. For a nonlinear control design, the more the structural characteristics are known, the better the structure can be controlled. However, the model parameters of the structural nonlinearity are often unknown, and estimations of these parameters are necessary.

Considering the estimation problem of nonlinear structures, the unscented Kalman filter (UKF) method has been used for parameter identification. The UKF utilizes the unscented transform (UT) to estimate the propagated mean and covariance. The unscented transform, which is the key to UKF, uses specially arranged points, which are called sigma points, to go through nonlinear transforms to estimate the updates of the mean and covariance. UKF was demonstrated to be more effective and accurate than the linearized counterpart of the Kalman filter, the extended Kalman filter. The two methods were compared in the articles written in [17-20]. It is a well-known procedure 
that has been applied to many real-time control systems. There are many studies of UKF combined with different control methods, such as fault-tolerant controls, model predictive controls [21-23], LQR controls [24], PID controls and its variants $[25,26]$, feedback linearization controls [27], and sliding mode controls [28]. However, when dealing with parameter identification of the systems possessing latent parameters, the results of UKF identification become less satisfactory. Latent parameters are those parameters that link indirectly with the observations. The Bouc-Wen model possesses two latent parameters. The states of the Bouc-Wen model are continuous. States change very little when using small integration step size. How to solve this problem for the Bouc-Wen model is important for the parameter identification and the controller design problems.

Based on the estimation results, various control algorithms can be designed for structural nonlinear vibration. Regarding nonlinear control methods, the sliding mode control (SMC) shows its prominence in quick response, insensitivity to disturbances in the structure, and ease of use [28-33]. When specific purposes and performances are expected, model reference controls are often used. In vibration mitigation, a zero reference can induce large control forces, which is often unrealistic for the control actuator to realize. A structure with large damping was mostly used as the reference system [34-39].

To realize an active control in civil structures, a commonly used control device is the active mass damper (AMD). An AMD generates control force through active motors and applies the force to structures by means of additional masses. Significant progress about using AMD to control structural vibration has been made in civil engineering [40-45]. Some studies are conducted to control structural nonlinear vibration using AMD. Li et al. [46] proposed a fuzzy logic control algorithm for structural nonlinear vibration control, which does not need the structure model. Incorporating the structural model into the controller design will benefit the control analysis and effect. However, fuzzy control is based on the fuzzy rule which is specified by the expert experience. Without a good mathematical model, fuzzy control may not have a good control effect especially for structural nonlinearities which are very complicated. In order to overcome this problem, a modified UKF is proposed in this paper to estimate unknown parameters and states. Based on this information, a reasonable controller can be proposed to control structural nonlinear vibration.

In this paper, MRSMC is combined with UKF to solve the problem of vibration mitigation of a structure that contains nonlinearities. The UKF is used to identify the parameters and estimate the unknown structural states. To improve the performance of parameter identification, the hysteretic state of the Bouc-Wen model is calculated by substituting the identified values in the last step into the equilibrium equation. The obtained state is used as one of the observations in the current step to update the identification. Using the information estimated by UKF, MRSMC is used to determine the control law from these states and parameters. The reference model used for MRSMC is the structure model with TMD. The efficiency of MRSMC-UKF is studied by simulation. The numerical results demonstrate the effectiveness of this combined MRSMC-UKF method.

\section{Modified UKF}

To acquire all the states and parameters, an effective identification method is required. In this section, a modified UKF method is developed to effectively identify the unknown states and parameters in a hysteretic model. Traditional UKF used to identify the parameter is reviewed in the following subsection.

2.1. State Estimation Using a Traditional UKF. UKF addresses the nonlinear system with the state space form as follows:

$$
\begin{aligned}
\mathbf{m}_{k} & =f\left(\mathbf{m}_{k-1}, \mathbf{u}_{k-1}\right)+\overline{\mathbf{w}}_{k-1}, \\
\mathbf{n}_{k} & =H\left(\mathbf{m}_{k}, \mathbf{u}_{k}\right)+\overline{\mathbf{v}}_{k},
\end{aligned}
$$

where $f(\cdot)$ is the nonlinear state function, $H(\cdot)$ is the observation function, $\mathbf{m}$ is the state vector of the system, $\mathbf{u}$ is the input vector of the system, and $\mathbf{n}$ is the observation vector. The parameters $\overline{\mathbf{w}}_{k-1}$ and $\overline{\mathbf{v}}_{k}$ are, respectively, the process noise and the observation noise vectors, and they are assumed to be Gaussian.

Generally, for parameter identification, the parameters are regarded as states, and then, the parameters are estimated together with the states:

$$
\mathbf{x}=\left[\begin{array}{ll}
\mathbf{m}^{T} & \boldsymbol{\theta}^{T}
\end{array}\right]^{T}
$$

where $\boldsymbol{\theta}$ is the parameter vector of the system and $\mathbf{x}$ is the augmented state vector.

2.2. Modification of the UKF. With the uncertainty of the parameters and states, the unknown states and related parameters are often more difficult to identify using the traditional UKF. Fortunately, states in civil engineering are always continuous, and parameters are mostly varying slowly. It is, therefore, feasible to constrain the freedom of the parameter estimation along the time. In the modified $\mathrm{UKF}$, states and parameters estimated in the last step are used to estimate the current states to offer the historical information as a reference by showing the consistency of the parameters and continuity of the states.

In the modified method, the states are divided into two groups, the direct states $\mathbf{x}_{d}$ and the latent states $\mathbf{x}_{l}$. The latent states usually have their own evolving process, which has no observation variables. After each step, the latent states are estimated again as $\hat{x}_{l}^{++}$by substituting other estimated states and parameters into the force equilibrium equation. This estimation is used as the observation of the next step: 


$$
\begin{gathered}
\mathbf{x}_{k}=\left[\begin{array}{c}
\mathbf{x}_{l k} \\
\mathbf{x}_{d k} \\
\boldsymbol{\theta}_{k}
\end{array}\right]=\left[\begin{array}{c}
f_{1}\left(\mathbf{x}_{l k-1}, \mathbf{x}_{d k-1}, \mathbf{u}_{k-1}\right) \\
f_{2}\left(\mathbf{x}_{l k-1}, \mathbf{x}_{d k-1}, \mathbf{u}_{k-1}\right) \\
\boldsymbol{\theta}_{k-1}
\end{array}\right]+\mathbf{w}_{k-1}, \\
\mathbf{y}_{k}=\left[\begin{array}{c}
\mathbf{n}_{k} \\
\hat{x}_{l k}^{++}
\end{array}\right]=\left[\begin{array}{c}
H\left(\mathbf{x}_{l k-1}, \mathbf{x}_{d k-1}, \mathbf{u}_{k-1}\right) \\
g_{1}\left(\mathbf{x}_{d k-1}, \boldsymbol{\theta}_{k-1}, \mathbf{u}_{k-1}\right)
\end{array}\right]+\mathbf{v}_{k},
\end{gathered}
$$

where $f_{1}$ and $f_{2}$ represent the state update functions corresponding to $\mathbf{x}_{d}$ and $\mathbf{x}_{l}$, respectively. $\mathbf{x}_{k}$ and $\mathbf{y}_{k}$ stand for the augmented state and observation vectors, respectively. $\widehat{\mathbf{x}}_{l k}^{++}$is calculated by $g_{1}$ and is the estimation of the latent variables, used as observation for better estimating the state. $g_{1}$ is the expression of $\mathbf{x}_{l}$ with respect to $\mathbf{x}_{d}$ and $\mathbf{u} . g_{1}$ is calculated with the force equilibrium equation $\mathbf{x}_{l}=f_{1}\left(\mathbf{x}_{l}, \mathbf{x}_{d}, \mathbf{u}\right) . \mathbf{w}_{k-1}$ and $\mathbf{v}_{k}$ are the augmented process and observation noise, with their covariance matrices being $\mathbf{Q}_{k-1}$ and $\mathbf{R}_{k}$, respectively.

Since the states of the system are continuous in time, when the time step is small, variance of a state is predictably small. This variance can be counted as the additive noise. In spite of a new uncertain observation being introduced, the latent variable is confined in a smaller range, which will largely increase the accuracy of the estimation as a whole. The detailed procedure of the modified UKF identification method is summarized in Appendix A.

\section{Model Reference Slide Mode Control (MRSMC)}

3.1. Simulation Model and Control Design. The initial structural model is a 3-story shear frame structure, and the nonlinear behavior exists in the structure. In order to study the effect of control force in the nonlinear field, the BoucWen model is used to model the nonlinear restoring force between stories and the control goal is to reduce the displacement of the third story relative to the ground. In this paper, the AMD control system is installed at the top of the structure. The system schematic diagram is shown in Figure 1.

3.2. Model of the AMD Control System. In this work, the stiffness and damping elements of the AMD system are obtained by the design method of the optimum TMD parameters equation [47] and the active force of the AMD system is designed by the MRSMC control method.

The displacement states of the controlled system are defined as $\mathbf{x}=\left[\begin{array}{llll}x_{1} & x_{2} & x_{3} & x_{4}\end{array}\right]^{T}$ and $\mathbf{y}=\left[\begin{array}{lll}y_{1} & y_{2} & y_{3}\end{array}\right]^{T}$, where $x_{1}, x_{2}$, and $x_{3}$ are the displacements against the ground, $x_{4}$ is the displacement of the AMD mass relative to the third story, and $y_{i}$ is the interstory displacement. The parameter $z_{i}$ is a dimensionless hysteretic displacement. $\alpha$, $A, \beta, \gamma, n$, and $D_{y}$ are the parameters of the Bouc-Wen model, $D_{y}$ is a parameter controls the magnitude of the hysteretic force of the Bouc-Wen model, and $U$ is the active force generated by the actuator of the AMD. The parameters $m_{a}, k_{a}$, and $c_{a}$ are the parameters of the AMD system. Setting

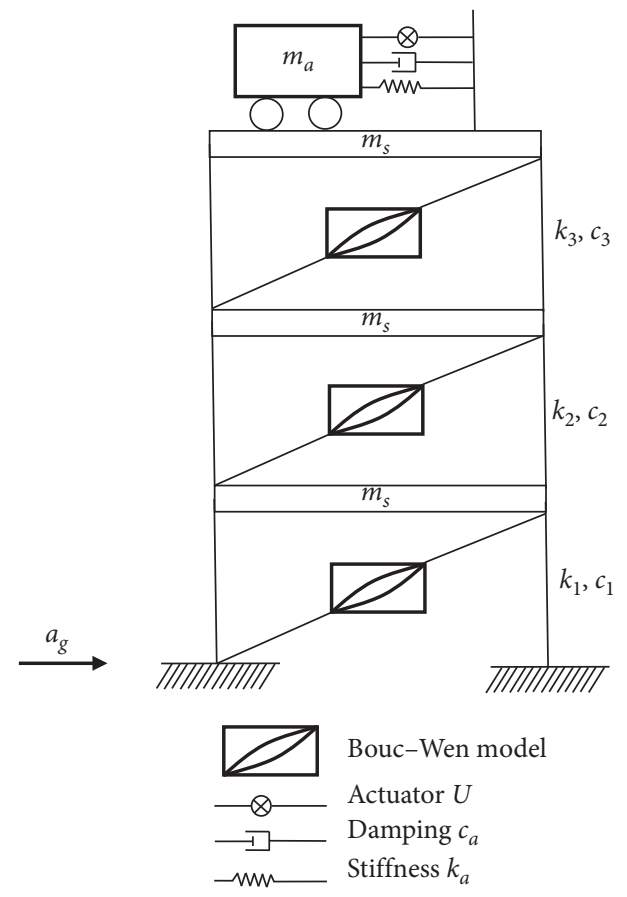

FIgURE 1: Schematic diagram of AMD controlled system.

a value to the ratio of the AMD mass to the main mass $\mu=m_{a} / 3 m_{s}$, the parameter values of the AMD system can be solved from the optimum TMD parameters equation, as shown in the following equation [47]:

$$
\begin{aligned}
& \beta_{a}=\frac{\omega_{a}}{\omega_{0}}=\frac{\sqrt{1-(\mu / 2)}}{1+\mu}, \\
& \zeta_{a}=\sqrt{\frac{\mu(1-(\mu / 4))}{4(1+\mu)(1-\mu / 2)}} .
\end{aligned}
$$

The equilibrium equation for an AMD system excited by the ground acceleration $a_{g}$ can be expressed as

$$
m_{a}\left(\ddot{x}_{3}+\ddot{x}_{4}+a_{g}\right)+k_{a} x_{4}+c_{a} \dot{x}_{4}=U \text {. }
$$

The equilibrium equation of the main structure excited by the ground acceleration is

$$
\begin{gathered}
\mathbf{M} \ddot{\mathbf{x}}_{l}+\mathbf{C} \dot{\mathbf{x}}_{l}+\mathbf{K} \mathbf{x}_{l}+\mathbf{L} \mathbf{K}_{n} \mathbf{z}=-m_{s} \mathbf{e} a_{g}-\mathbf{f}_{c}, \\
\dot{z}_{i}=\frac{1}{D_{y i}}\left(A_{i} \dot{y}_{i}-\beta\left|\dot{y}_{i}\right|\left|z_{i}\right|^{n-1}-\gamma_{i} \dot{y}_{i}\left|z_{i}\right|^{n}\right), \quad i=1,2,3,
\end{gathered}
$$

$\mathbf{x}_{l}=\left[x_{1}, x_{2}, x_{3}\right]^{T}, \quad \mathbf{M}=m_{s} \mathbf{I}, \quad \mathbf{C}=\left[\begin{array}{ccc}c_{1}+c_{2} & -c_{2} \\ -c_{2} & c_{2}+c_{3} & -c_{3} \\ & -c_{3} & c_{3}\end{array}\right]$, $\mathbf{K}=\left[\begin{array}{ccc}\alpha_{1} k_{1}+\alpha_{2} k_{2} & -\alpha_{2} k_{2} & \\ -\alpha_{2} k_{2} & \alpha_{2} k_{2}+\alpha_{3} k_{3} & -\alpha_{3} k_{3} \\ & -\alpha_{3} k_{3} & \alpha_{3} k_{3}\end{array}\right], \quad \mathbf{L}=\left[\begin{array}{ccc}-c_{3} & c_{3} \\ & -1 & -1 \\ & 1\end{array}\right]$, $\mathbf{K}_{n}=\left[\begin{array}{lll}\left(1-\alpha_{1}\right) k_{1} D_{y 1} & & \\ & \left(1-\alpha_{2}\right) k_{2} D_{y 2} & \\ & & \left(1-\alpha_{3}\right) k_{3} D_{y 3}\end{array}\right]$, $\mathbf{z}=\left[z_{1}, z_{2}, z_{3}\right]^{T}, \quad \mathbf{e}=[1,1,1]^{T}, \quad$ and $\quad \mathbf{f}_{c}=\left[0,0, U-k_{a} x_{4}\right.$ $\left.-c_{a} \dot{x}_{4}\right]^{T}$. From the equation (6a), we can get the following equation: 


$$
\begin{aligned}
m_{s} \ddot{x}_{3}= & c_{3} \dot{x}_{2}-c_{3} \dot{x}_{3}+\alpha_{3} k_{3} x_{2}-\alpha_{3} k_{3} x_{3} \\
& -\left(1-\alpha_{3}\right) k_{3} D_{y 3} z_{3}-m_{s} a_{g}-U+k_{a} x_{4}+c_{a} \dot{x}_{4} .
\end{aligned}
$$

Substituting this equation into equation (5), the equilibrium equation for the AMD system can be written as

$$
\begin{aligned}
m_{a} \ddot{x}_{4}= & -\frac{m_{a}}{m_{s}}\left(c_{3} \dot{x}_{2}-c_{3} \dot{x}_{3}+\alpha_{3} k_{3} x_{2}-\alpha_{3} k_{3} x_{3}-\left(1-\alpha_{3}\right)\right. \\
& \left.\cdot k_{3} D_{y 3} z_{3}\right)+\left(1+\frac{m_{a}}{m_{s}}\right)\left(U-k_{a} x_{4}-c_{a} \dot{x}_{4}\right) .
\end{aligned}
$$

The governing equations of the AMD control system are expressed as equations (5), (6a), and (6b). Combining those two equations gives the motion equation of the AMD system as follows:

$$
\begin{aligned}
& \mathbf{M}_{p} \ddot{\mathbf{x}}+\mathbf{C}_{p} \dot{\mathbf{x}}+\mathbf{F}_{p}(\mathbf{x}, \mathbf{z})=\mathbf{M}_{e} a_{g}+\mathbf{H}_{p} U,
\end{aligned}
$$

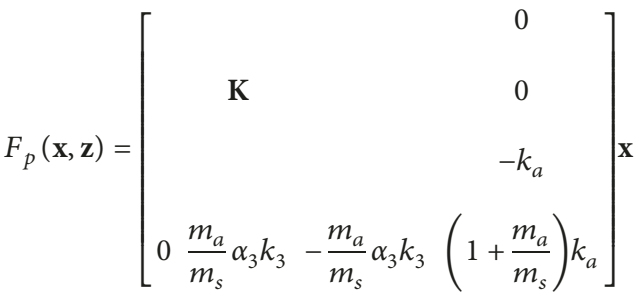

$$
\begin{aligned}
& +\left[\begin{array}{lll}
\mathbf{L} \\
0 & 0 & -\frac{m_{a}}{m_{s}}
\end{array}\right] \mathbf{K}_{n} \mathbf{z}
\end{aligned}
$$

where $M_{p} \in R^{4 \times 4}$ and $C_{p} \in R^{4 \times 4}$ are the mass and damping matrices, respectively, while $x, \dot{x}$, and $\ddot{x}$ represent the displacement, velocity, and acceleration vectors of the AMD control system, respectively.

Specifically,

$$
\begin{aligned}
& \mathbf{M}_{p}=\left[\begin{array}{rrrr} 
& & & 0 \\
& & & 0 \\
0 & 0 & 0 & m_{a}
\end{array}\right],
\end{aligned}
$$

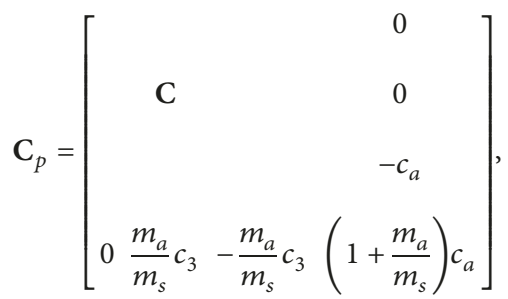

$$
\begin{aligned}
& M_{e}=\left[\begin{array}{llll}
-m_{s} & -m_{s} & -m_{s} & 0
\end{array}\right]^{T} \text {, } \\
& H_{p}=\left[\begin{array}{llll}
0 & 0 & -1 & \left(1+\frac{m_{a}}{m_{s}}\right)
\end{array}\right]^{T} \text {, } \\
& \mathbf{y}=\mathbf{L}^{T} \mathbf{x},
\end{aligned}
$$

where $H_{p}$ is the force location vector and $y$ is the interstory displacement of the model.
3.3. Reference Model. For vibration control, the sliding mode control can make the controlled states track the desired states. It is the best effect to let the controlled state approach zero; however, the AMD provides the control force mainly by the inertia of the mass. When the active force $U$ is equal to zero, the above AMD system changes into a TMD system. Therefore, in this paper, the TMD control system is considered the reference model. The mathematical model of the reference model is defined as

$$
\begin{array}{r}
M_{m} \ddot{x}_{m}+C_{m} \dot{x}_{m}+F_{m}\left(x_{m}, z\right)=M_{m} a_{g}, \\
\dot{z}_{i}=\frac{1}{D_{y i}}\left(A_{i} \dot{y}_{m i}-\beta\left|\dot{y}_{m i}\right|\left|z_{i}\right|^{n-1}-\gamma_{i} \dot{y}_{m i}\left|z_{i}\right|^{n}\right), \quad i=1,2,3,
\end{array}
$$

where $M_{m}=M_{P}, C_{m}=C_{p}, F_{m}=F_{p}, M_{m}=M_{e}$, and the other parameters are defined as above.

\section{MRSMC-UKF Control Law}

In this paper, our goal is to reduce the third-story displacement and control the displacement of the AMD system. The signal error is defined as $e=a\left(x_{3}-x_{d 3}\right)+b\left(x_{4}-x_{d 4}\right)$. $a$ and $b$ are displacement parameters in which proper values are obtained by the optimal parameter module in Simulink. The control effect is to make the selected signal error $e$ approach to zero gradually. $x_{d 3}$ and $x_{d 4}$ are the states that we want to track. In this simulation, we assume that $x_{d 3}=$ $w_{1} x_{m 3}$ and $x_{d 4}=w_{2} x_{m 4}$, where $x_{m 3}$ and $x_{m 4}$ are the states of the reference model and the $w_{1}$ and $w_{2}$ are coefficients.

The sliding mode surface is defined as

$$
S=C_{C} e+\dot{e}
$$

where $C_{c}>0$.

The Lyapunov function candidate can be defined as $V=1 / 2\left(S m_{S} S\right)$. Then,

$$
\begin{aligned}
\dot{V}= & S m_{s} \dot{S}=S m_{s}\left(C_{C} \dot{e}+a \ddot{x}_{3}+b \ddot{x}_{4}\right) \\
= & S\left[m_{s} C_{c} \dot{e}-a w_{1} m_{s} \ddot{x}_{d 3}-b w_{2} m_{s} \ddot{x}_{d 4}+(a-b)\right. \\
& \cdot\left(c_{3} \dot{x}_{2}-c_{3} \dot{x}_{3}+\alpha_{3} k_{3} x_{2}-\alpha_{3} k_{3} x_{3}-\left(1-\alpha_{3}\right) k_{3} D_{y 3} z_{3}\right) \\
& \left.-a m_{s} a_{g}-\left(a-\left(1+\frac{1}{3 \mu}\right) b\right)\left(U-k_{a} x_{4}-c_{a} \dot{x}_{4}\right)\right] .
\end{aligned}
$$

Therefore, the active force $U$ can be defined as

$$
\begin{aligned}
U= & \frac{1}{a-(1+(1 / 3 \mu)) b} \\
& {\left[m_{s} C_{c} \dot{e}-a w_{1} m_{s} \ddot{x}_{d 3}-b w_{2} m_{s} \ddot{x}_{d 4}+(a-b)\right.} \\
& \cdot\left(c_{3} \dot{x}_{2}-c_{3} \dot{x}_{3}+\alpha_{3} k_{3} x_{2}-\alpha_{3} k_{3} x_{3}-\left(1-\alpha_{3}\right) k_{3} D_{y 3} z_{3}\right) \\
& \left.+a m_{s} D \cdot \operatorname{sign}(S)\right]+k_{a} x_{4}+c_{a} \dot{x}_{4},
\end{aligned}
$$


where $\left|a_{g}\right| \leq D$ and $D$ is an approximate rather than a strict upper bound value of an earthquake that is an external input. Substituting equation (14) into equation (13), the derivative of $V$ can be rewritten as

$$
\begin{aligned}
\dot{V} & =S\left(-a \cdot m_{s} \cdot a_{g}-a \cdot m_{s} \cdot D \cdot \operatorname{sign}(S)\right) \\
& =-a \cdot m_{s}\left(a_{g} \cdot S+D \cdot \operatorname{sign}(S)\right) \leq 0 .
\end{aligned}
$$

If equation (15) is satisfied, the control law $U$ designed by equation (14) can guarantee the controlled system is stable by the Lyapunov stability theory. Only when $S=0$ can we get $\dot{V}=0$. Since $C_{C}>0$, in equation (12), we can derive that

$$
e \longrightarrow 0 \text {. }
$$

From LaSalle's theorem and the work of Xu and Özgüner [48], the active force $U$ can realize the following equation:

$$
\begin{aligned}
& x_{3} \longrightarrow x_{d 3}, \\
& x_{4} \longrightarrow x_{d 4} .
\end{aligned}
$$

Regarding the control force (14), there is a sign function in the control force which will cause the chattering phenomenon [40, 49]. In this paper, an inverse tangent function is used to approximate the sign function.

\section{Numerical Simulation}

MATLAB/SIMULINK is used for carrying out all simulations with a sampling frequency of $1000 \mathrm{~Hz}$ for a period of $100 \mathrm{~s}$. The flow chart of the simulation is shown in Figure 2.

Firstly, the states of the structure and the parameters were updated in real time with the UKF. Secondly, the active force can be solved based on the estimated states and the identified parameters.

In general, the acceleration of the structure is easy to measure; therefore, in the simulation, we assumed that only the acceleration state of the structure is known. To study the structure with uncertainties, we assumed that the parameters $k_{i}, \alpha, A, \beta$, and $\gamma$ are unknown. The parameters $n$ and $D_{y i}$ in the Bouc-Wen model have relatively little effect on the nonlinear behavior and are assumed to be known. The values of the structural parameters are shown in Table 1.

The El Centro earthquake with amplitude $490 \mathrm{Gal}$ is employed as the seismic excitation. The initial states of the structure are set to zero, and the mass ratio $\mu$ of the AMD control system is set to 0.05 . All the unknown parameters are assumed to be 0.6 times the actual value, respectively.

In the simulation, the coefficients of the sliding mode surface are defined as $C_{c}=2, a=3, b=0.1, w_{1}=0.5$, and $w_{2}=5$. For the $x_{3}$, the AMD control system based on MRSMC is better than the TMD system because of $w_{1}=0.5$. To improve the control of $x_{3}$ at the expense of magnifying the displacement of the AMD mass, we set $w_{2}$ to 5 , and the magnified displacement is in our acceptable range.

\subsection{State Estimation and Parameter Identification.} Equations (6a) and (6b) shows that there is a little correlation between the acceleration states $\ddot{x}$ and the unknown BoucWen parameters that are closely related to the values of

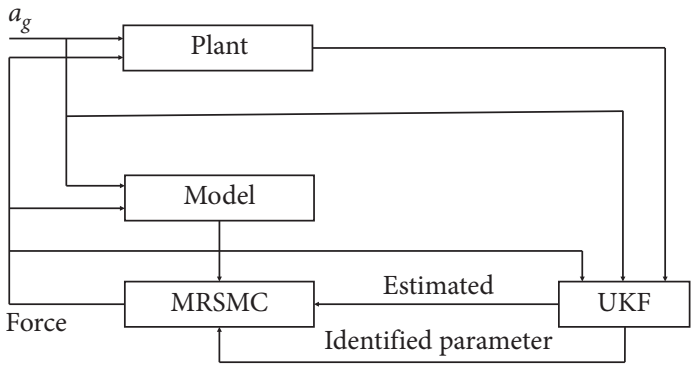

FIGURE 2: Flow chart of the simulation.

TABLE 1: Structural parameters for simulation.

\begin{tabular}{lccccc}
\hline Story & $m_{s}(\mathrm{t})$ & $k_{i}\left(10^{4} \mathrm{kN} / \mathrm{m}\right)$ & $c_{i}(\mathrm{kN} * \mathrm{~s} / \mathrm{m})$ & $D_{y i}(\mathrm{~cm})$ & $n$ \\
\hline 1 & & 9.315 & 545 & 1.9 & \\
2 & 345.6 & 7.605 & 445 & 1.7 & 5 \\
3 & & 6.165 & 359 & 1.5 & \\
\hline
\end{tabular}

state $z$. If the observations that are input to the UKF have little correlation with the unknown parameters, the identification effect will be poor. The state $z$ is also needed to be given to the UKF as the observation; however, the $z$ state is difficult to measure. In this paper, we propose a novel method. First, at time $k$, using the estimated values of the state and parameters, the calculated value of the active control force and the measured values of the external inputs and acceleration to calculate $z$ by the dynamic equation of the AMD control system are shown in equation (6a). Second, the measured value of acceleration at time $k$ and state $z$ is input to the UKF as the observed value at time $k$ to estimate the state and parameters at time $k+1$. The calculation formula of the $z$ state is expressed as

$$
\left\{\begin{aligned}
z_{1}^{e}= & \frac{1}{\left(1-\alpha_{1}\right) k_{1} D_{y 1}}\left[-c_{1} \dot{x}_{1}+c_{a} \dot{x}_{4}-\alpha_{1} k_{1} x_{1}+k_{a} x_{4}\right. \\
& \left.-m_{s}\left(\ddot{x}_{1}+\ddot{x}_{2}+\ddot{x}_{3}+3 a_{g}\right)-U\right], \\
z_{2}^{e}= & \frac{1}{\left(1-\alpha_{2}\right) k_{2} D_{y 2}}\left[c_{2} \dot{x}_{1}-c_{2} \dot{x}_{2}+c_{a} \dot{x}_{4}+\alpha_{2} k_{2} x_{1}\right. \\
& \left.-\alpha_{2} k_{2} x_{2}+k_{a} x_{4}-m_{s}\left(\ddot{x}_{2}+\ddot{x}_{3}+2 a_{g}\right)-U\right], \\
z_{3}^{e}= & \frac{1}{\left(1-\alpha_{3}\right) k_{3} D_{y 3}}\left[c_{3} \dot{x}_{2}-c_{3} \dot{x}_{3}+c_{a} \dot{x}_{4}+\alpha_{3} k_{3} x_{2}\right. \\
& \left.-\alpha_{3} k_{3} x_{3}+k_{a} x_{4}-m_{s}\left(\ddot{x}_{3}+a_{g}\right)-U\right] .
\end{aligned}\right.
$$

It should be noted that all the unknown variables in the above equation used the value estimated in real time. Figures 3 and 4 show the parameter identification effect using only the acceleration as the observation input and using both acceleration and the state $z$ as the observation input, respectively. The identified results are shown in Table 2. The state estimation results are shown in Figures 5-7, and the estimated 

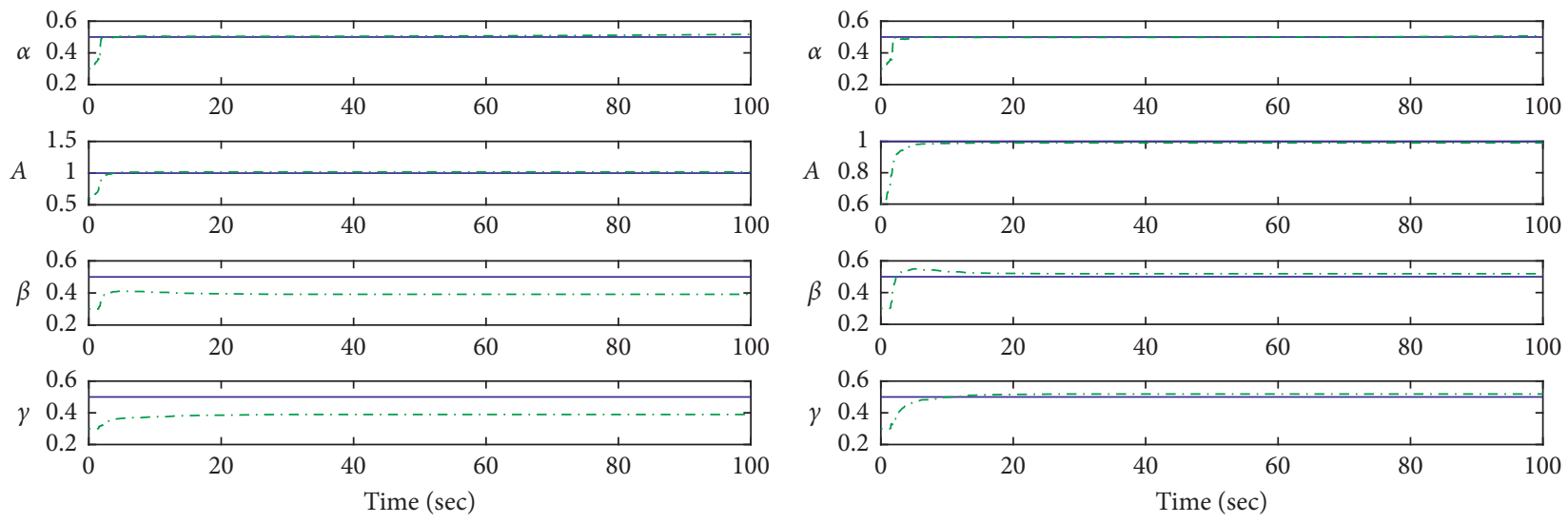

- Ture value

..- Identified value

_ Ture value

- - Identified value

(a)

(b)

FIGURE 3: Results of the Bouc-Wen parameter identification under different observations. (a) Only acceleration is input to UKF. (b) Both acceleration and state $z$ are input to UKF.
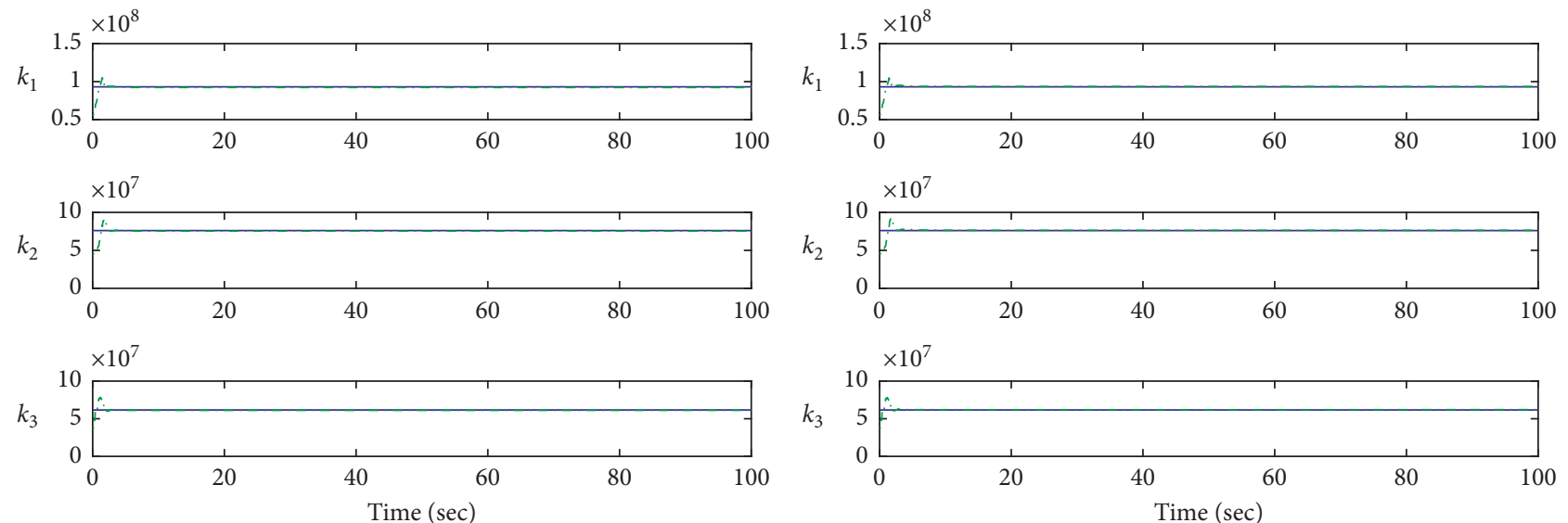

- True value Identified value

- True value
$\ldots$-. Identified value

(a)

(b)

FIgURE 4: Results of the stiffness identification under different observations. (a) Only acceleration is input to UKF. (b) Both acceleration and state $z$ are input to UKF.

TABLE 2: Identified value and error of the unknown parameters.

\begin{tabular}{|c|c|c|c|c|c|c|}
\hline \multirow[t]{2}{*}{ Parameters } & \multirow{2}{*}{ Actual value } & \multirow[t]{2}{*}{ Initial value } & \multicolumn{2}{|c|}{$\begin{array}{l}\text { Identified by augmented } \\
\text { observation }\end{array}$} & \multicolumn{2}{|c|}{ Identified by acceleration } \\
\hline & & & Value & Error $(\%)$ & Value & Error $(\%)$ \\
\hline$k_{1}\left(10^{7}\right)$ & 9.315 & 5.5890 & 9.3537 & 0.42 & 9.2308 & 0.9 \\
\hline$k_{2}\left(10^{7}\right)$ & 7.605 & 4.5630 & 7.6404 & 0.47 & 7.5410 & 0.84 \\
\hline$k_{3}\left(10^{7}\right)$ & 6.165 & 3.6990 & 6.2121 & 0.76 & 6.1211 & 0.71 \\
\hline$\alpha$ & 0.5 & 0.3 & 0.5070 & 1.41 & 0.5169 & 3.37 \\
\hline$A$ & 1 & 0.6 & 0.9906 & 0.94 & 1.0176 & 1.76 \\
\hline$\beta$ & 0.5 & 0.3 & 0.5190 & 3.80 & 0.3917 & 21.66 \\
\hline$\gamma$ & 0.5 & 0.3 & 0.5187 & 3.73 & 0.3893 & 22.13 \\
\hline
\end{tabular}




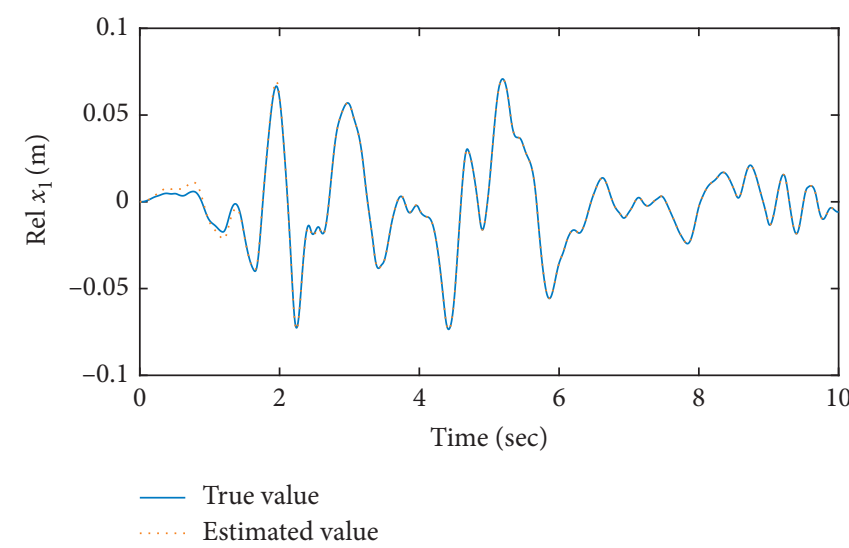

(a)

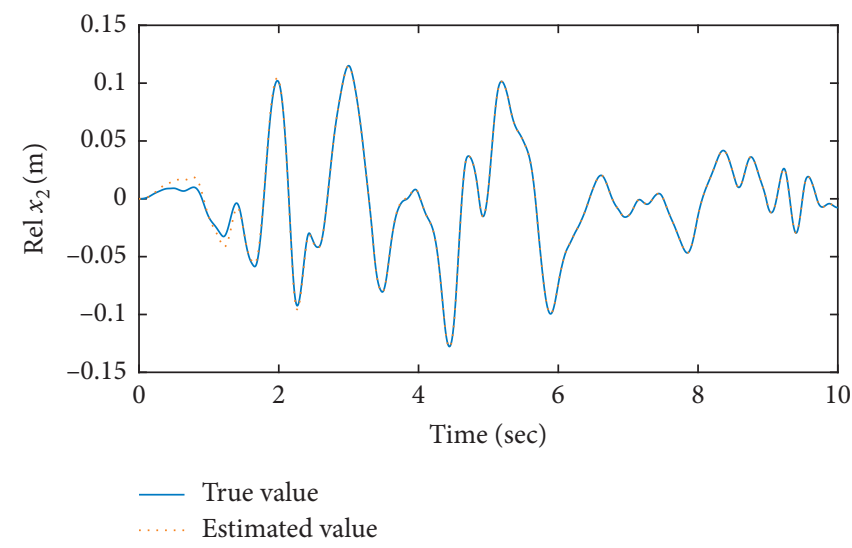

(b)

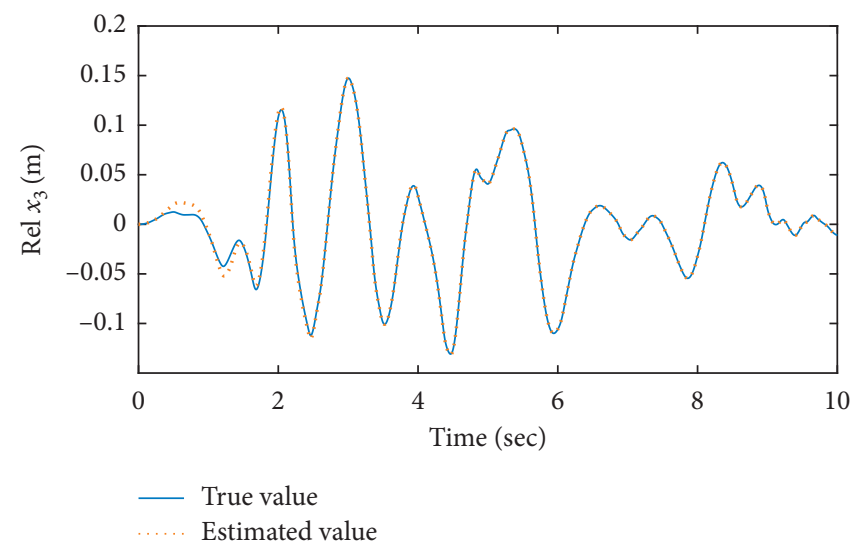

(c)

Figure 5: Comparison of structural displacement trajectory under MRSMC. (a) Displacement of the first story. (b) Displacement of the second story. (c) Displacement of the third story.

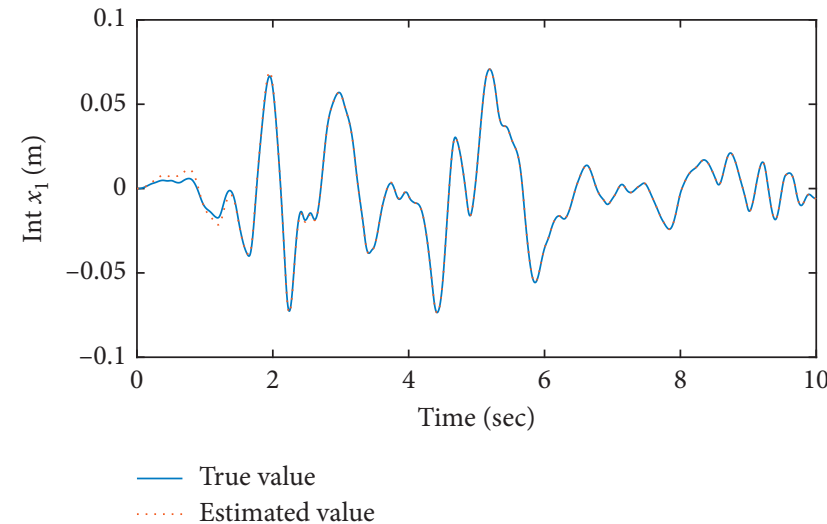

(a)

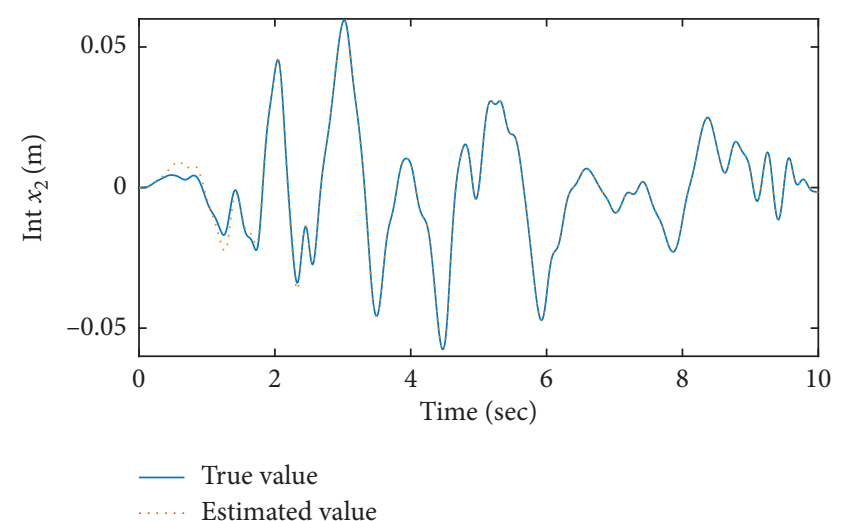

(b)

Figure 6: Continued. 


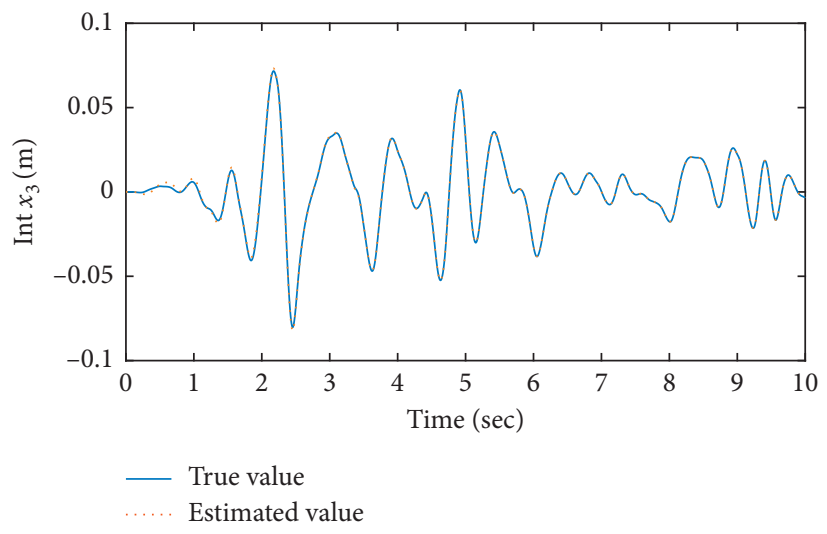

(c)

FIGURE 6: Comparison of structural interstory displacement trajectory under MRSMC. (a) Interstory displacement of the first story. (b) Interstory displacement of the second story. (c) Interstory displacement of the third story.

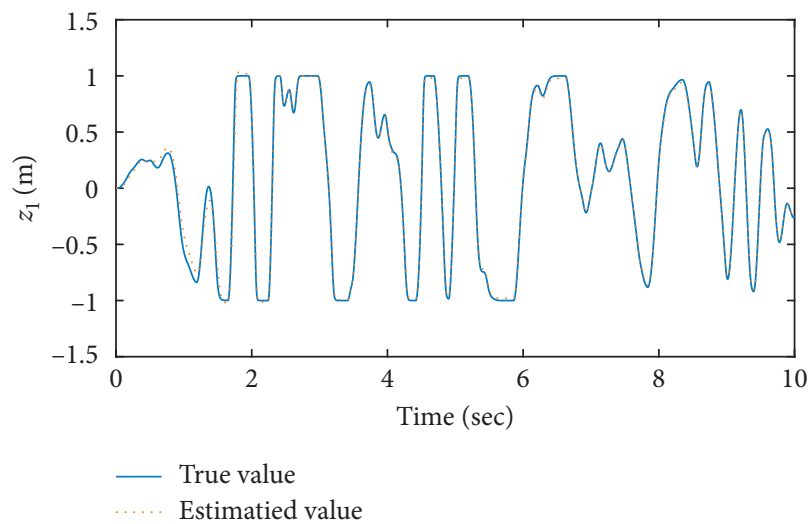

(a)

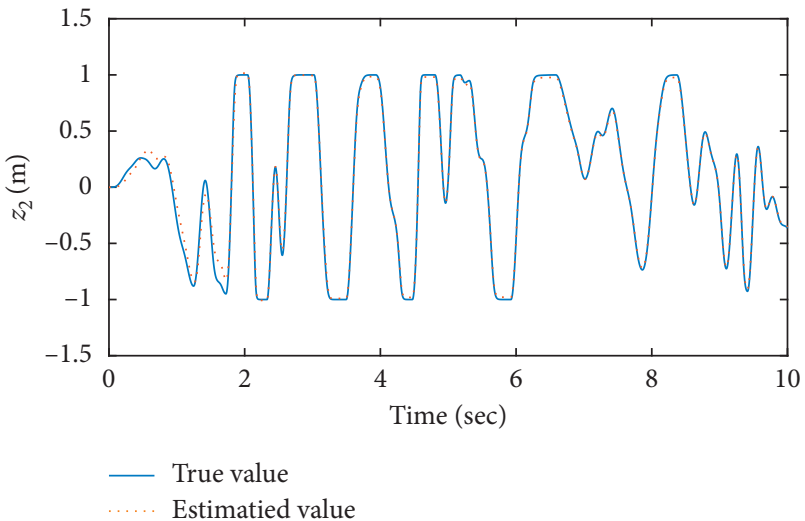

(b)

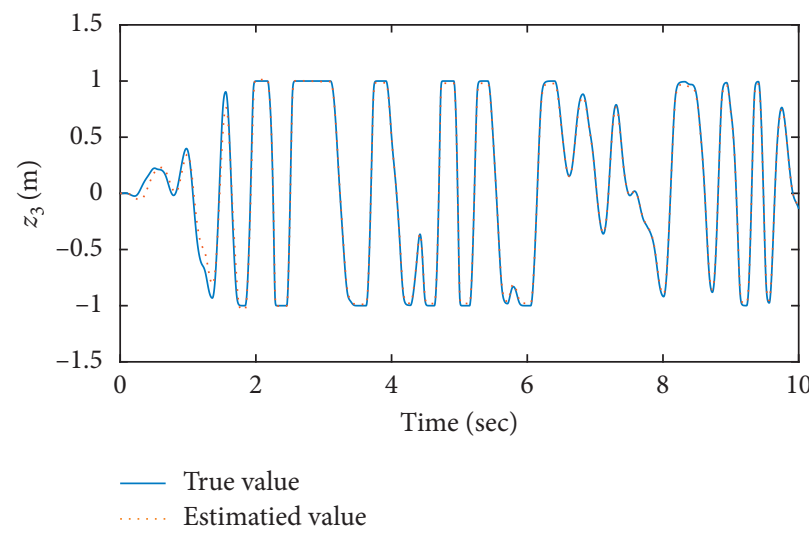

(c)

FiguRE 7: Dimensionless hysteretic displacement trajectory. (a) $z_{1}$. (b) $z_{2}$. (c) $z_{3}$.

states effectively converge the actual states. It is beneficial to obtain the control force when the UKF can identify the unknown parameters in a short time with a small error.

5.2. Control Results. For chattering reduction, the $\operatorname{sign}(\cdot)$ is replaced by $\arctan (\cdot)$ in equation (15) since the $\arctan (\cdot)$ function generates smooth control actions [37-39]. The control effect of AMD is compared with the response of the structure without control, and the TMD control system and the result of the control are shown in Figure 8. The control results of the interstory displacement are shown in Figure 9. The states of AMD mass are shown in Figure 10. The active force generated by the actuator is shown in Figure 11, and the value of the sliding surface is shown in Figure 12. 


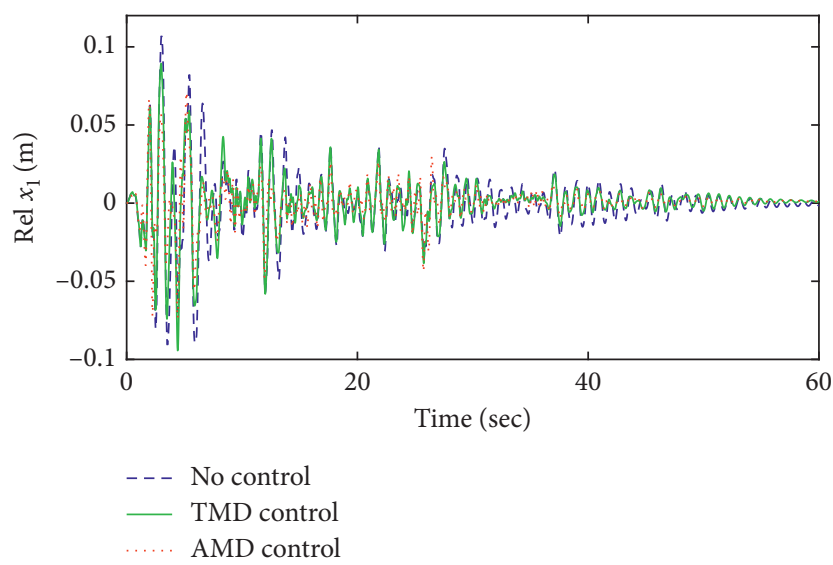

(a)

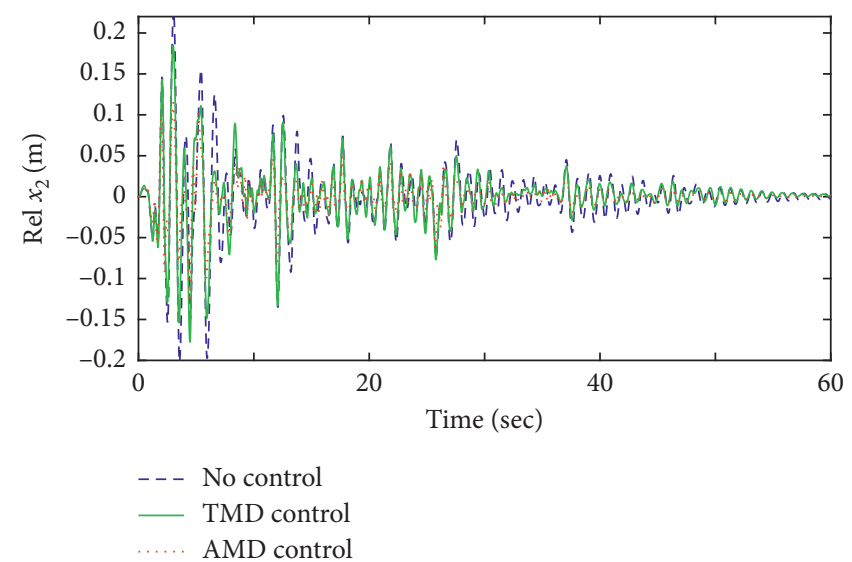

(b)

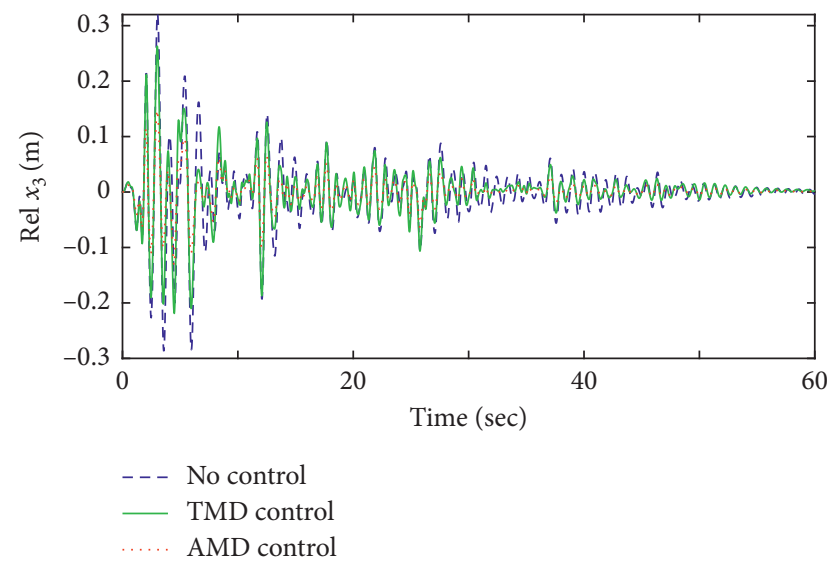

(c)

Figure 8: Comparison of each story response for different control strategies. (a) The 1st story response. (b) The 2nd story response. (c) The 3rd story response.

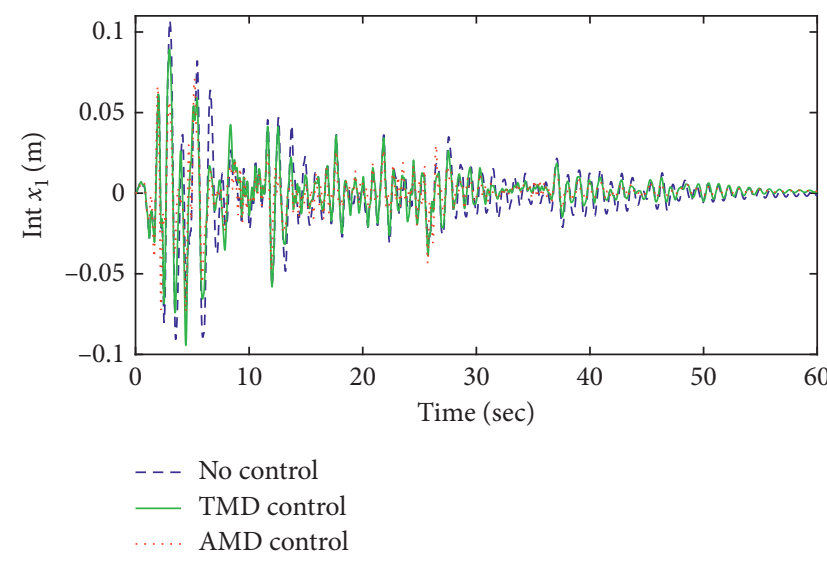

(a)

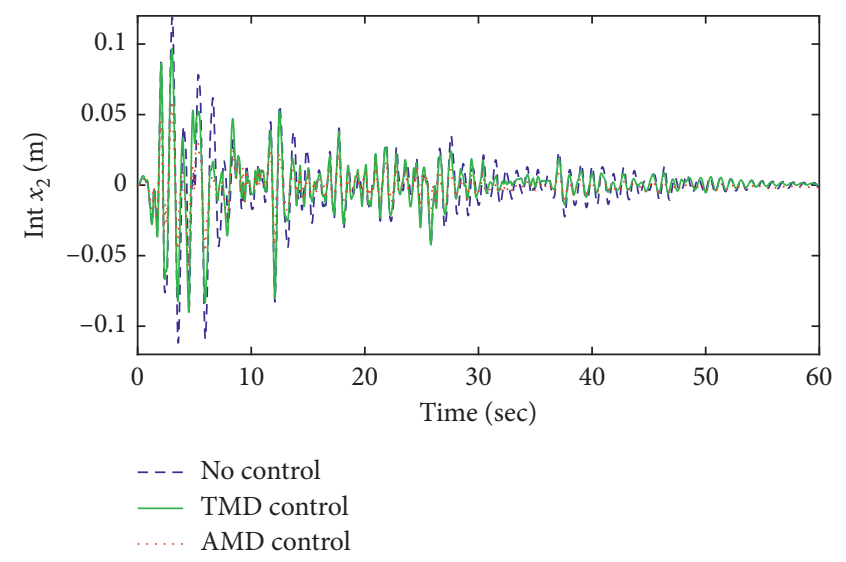

(b)

Figure 9: Continued. 


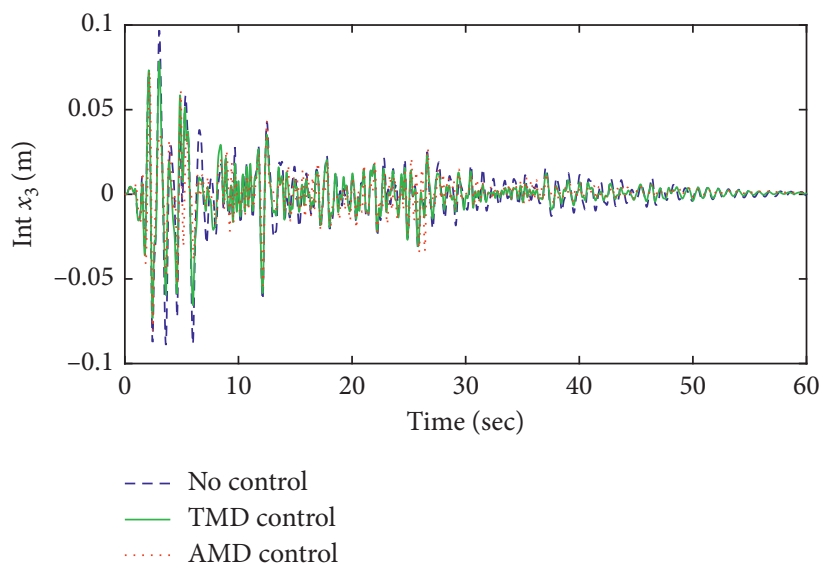

(c)

Figure 9: Comparison of each interstory displacement for different control strategies. (a) The 1st interstory displacement. (b) The 2nd interstory displacement. (c) The 3rd interstory displacement.
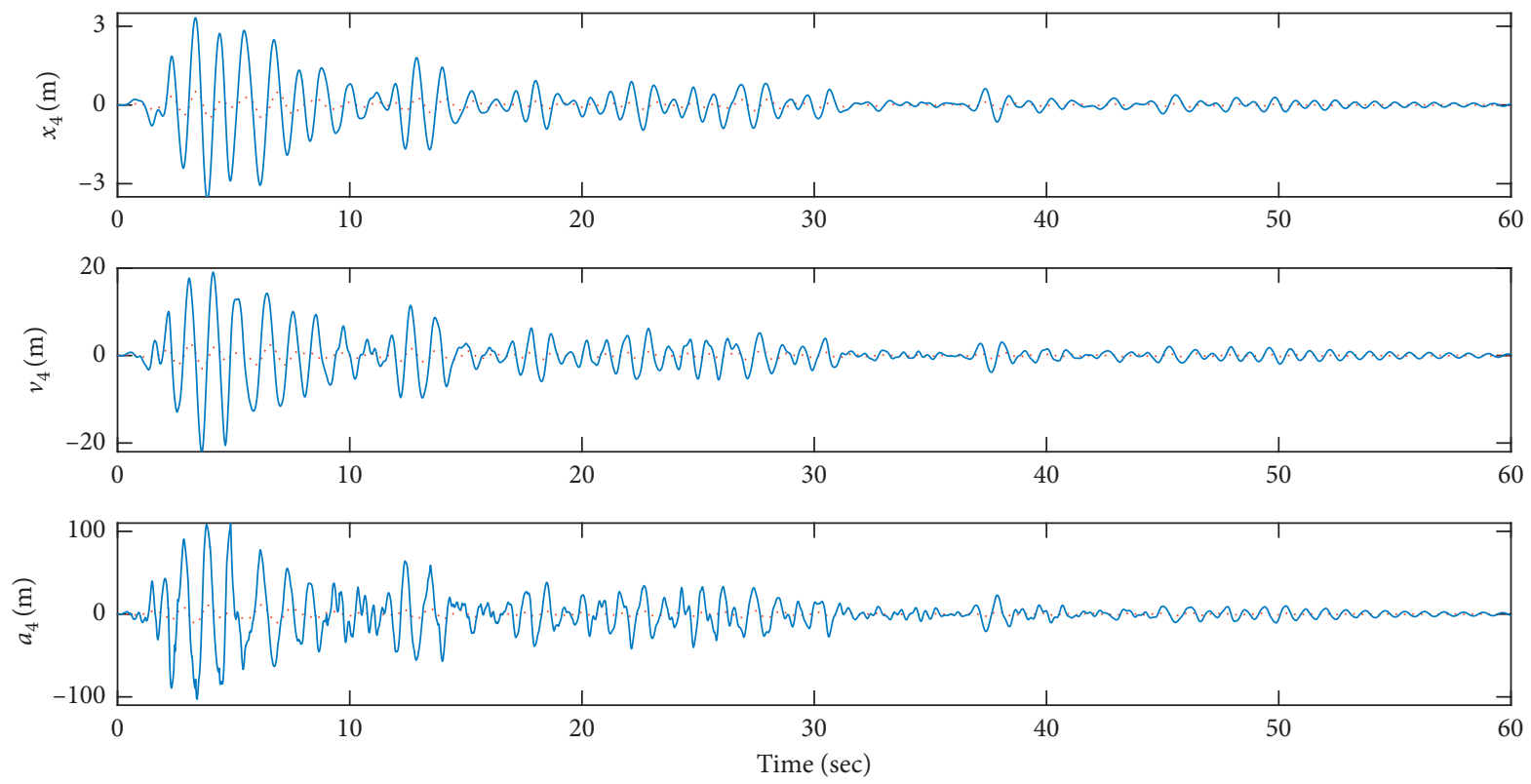

TMD control

- AMD control

FIgURE 10: Responses of AMD and TMD device.

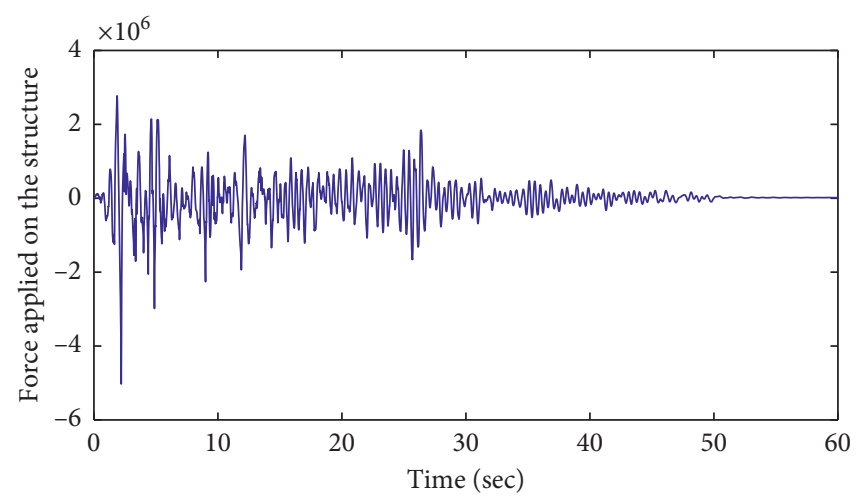

Figure 11: Applied active force. 


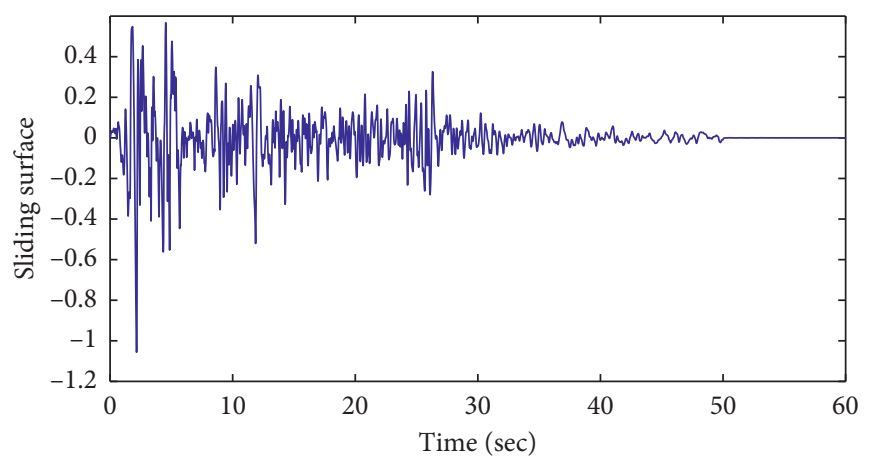

Figure 12: Convergence of the sliding surface.

In Table 3, different criterions are used to demonstrate the control effect of utilizing the method introduced in this paper. In terms of the maximum interstory drift, the control effect of the introduced AMD method is mostly far better than the TMD control effect in the control of the first two stories, though the control effect of these two methods in the third story is comparable. When the input potential of structure, which is expressed as the 2-norm of the interstory drift, is studied, the AMD control shows overwhelming advantage compared with the TMD control effect.

\section{Conclusions}

The vibration mitigation of a nonlinear structure using an active mass damper with an adaptive control design is studied in this paper, and the adaptive force is provided by the model reference sliding model control (MRSMC) method. Due to the unknown parameters in the system, this paper proposed a novel control method by combining the unscented Kalman filter (UKF) with the MRSMC to form the integrated MRSMC-UKF. The UKF is used to identify the unknown parameters and estimate the structural states, and the MRSMC is used to determine the control law by these states and parameters based on the information estimated by UKF. The numerical model is a nonlinear 3-story frame structure with the AMD device on the top floor. The Bouc-Wen model is used to model the nonlinear restoring force of the structure. The stiffness of the simulated structure and the parameters of the BoucWen model are assumed to be unknown, and these parameters are estimated in real time by using the proposed method based on the measured acceleration states. The control effect of AMD is compared with the responses of the structure without control and with the TMD control system. It turns out that the proposed MRSMC-UKF not only efficiently estimates the states and identifies the parameters but also effectively controls the structural nonlinear vibration. Based on the proposed method, a better active control device could be developed to suppress structural nonlinear vibration of the high-rise buildings under earthquake excitation. Moreover, other innovative active or semiactive control methods for structural nonlinear vibration may also be proposed since a good nonlinear mathematical model can be obtained by the modified UKF.
TABLE 3: Control effect under different criteria.

\begin{tabular}{lcccc}
\hline Story & $\frac{\max \mid d_{i}(t) \|_{\text {AMD control }}}{\max \mid d_{i}(t) \|_{\text {TMD control }}}$ & $\frac{\max \mid d_{i}(t) \|_{\text {AMD control }}}{\max \mid d_{i}(t) \|_{\text {No control }}}$ & $\frac{\left.\left\|d_{i}(t)\right\|_{2}\right|_{\text {AMD control }}}{\left.\left\|d_{i}(t)\right\|_{2}\right|_{\text {TMD control }}} \frac{\left.\left\|d_{i}(t)\right\|_{2}\right|_{\text {AMD control }}}{\left.\left\|d_{i}(t)\right\|_{2}\right|_{\text {No control }}}$ \\
\hline 1 & $78.05 \%$ & $68.78 \%$ & $75.07 \%$ & $62.56 \%$ \\
2 & $61.67 \%$ & $50.13 \%$ & $53.71 \%$ & $44.36 \%$ \\
3 & $102.67 \%$ & $83.28 \%$ & $84.95 \%$ & $70.38 \%$ \\
\hline
\end{tabular}

\section{Appendix}

In this appendix the procedure of the modified UKF method is presented as follows:

First, initialize the algorithm with

$$
\begin{aligned}
& \widehat{\mathbf{x}}_{0}^{+}=E\left(\mathbf{x}_{0}\right), \\
& \mathbf{P}_{0}^{+}=E\left[\left(\mathbf{x}_{0}-\widehat{\mathbf{x}}_{0}^{+}\right)\left(\mathbf{x}_{0}-\widehat{\mathbf{x}}_{0}^{+}\right)^{T}\right],
\end{aligned}
$$

where $\hat{\square}$ represents the estimation of the corresponding variable, $\mathbf{x}_{0}$ is the initial value of the states, $\widehat{\mathbf{x}}_{0}^{+}$is the first estimation of $\mathbf{x}_{0}, \mathbf{P}_{0}$ is the estimated covariance of $\mathbf{x}_{0}$; by the same principle, $\mathbf{P}_{\square}$ is the estimated covariance of $\mathbf{x}_{\square}$, and $E(\square)$ calculates the expectation of a random variable.

Then, the algorithm starts.

At the $k$-th step,

Use $\widehat{\mathbf{x}}_{k-1}^{+}$, which is the estimation of $\mathbf{x}_{k-1}$ at the $k-1$-th step, to formulate the sigma point vectors $\widehat{\mathbf{x}}_{k-1}^{(i)}$ :

$$
\widehat{\mathbf{x}}_{k-1}^{(i)}=\widehat{\mathbf{x}}_{k-1}^{+}+\widetilde{\mathbf{x}}^{(i)}, \quad i=1, \ldots, 2 n,
$$

where $\quad \widetilde{\mathbf{x}}^{(i)}=\left(\sqrt{n \mathbf{P}_{k-1}^{+}}\right)_{i}^{T}, \quad i=1, \ldots, n \quad$ and $\quad \widetilde{\mathbf{x}}^{(i+n)}=$ $-\left(\sqrt{n \mathbf{P}_{k-1}^{+}}\right)_{i}^{T}, i=1, \ldots, n$

Calculate the estimated latent state $\widehat{\mathbf{x}}_{l k}^{++}$with

$$
\widehat{\mathbf{x}}_{l k}^{++}=g_{1}\left(\mathbf{x}_{d k-1}, \boldsymbol{\theta}_{k-1}, \mathbf{u}_{k-1}\right) .
$$

Substitute the sigma points into the system model to obtain the updated sigma points $\widehat{\mathbf{x}}_{k}^{(i)}$ :

$$
\widehat{\mathbf{x}}_{k}^{(i)}=f\left(\widehat{\mathbf{x}}_{k-1}^{(i)}, \mathbf{u}_{k-1}\right), \quad i=1, \ldots, 2 n .
$$

With these updated sigma points, the first estimations of the mean and covariance of the states in step $k$ are

$$
\begin{aligned}
& \widehat{\mathbf{x}}_{k}^{-}=\frac{1}{2 n} \sum_{i=1}^{2 n} \widehat{\mathbf{x}}_{k}^{(i)}, \\
& \mathbf{P}_{k}^{-}=\frac{1}{2 n} \sum_{i=1}^{2 n}\left(\widehat{\mathbf{x}}_{k}^{(i)}-\widehat{\mathbf{x}}_{k}^{-}\right)\left(\widehat{\mathbf{x}}_{k}^{(i)}-\widehat{\mathbf{x}}_{k}^{-}\right)+\mathbf{Q}_{k-1} .
\end{aligned}
$$

Substituting the sigma points into the observation function gives

$$
\widehat{\mathbf{n}}_{k}^{(i)}=H\left(\widehat{\mathbf{x}}_{k}^{i}, \mathbf{u}_{k}\right) .
$$

From the sigma points of the observation vector $\widehat{\mathbf{y}}_{k}^{(i)}=\left[\begin{array}{c}\widehat{\mathbf{n}}_{k}^{(i)} \\ \widehat{\mathbf{x}}_{l k}^{(i)}\end{array}\right], \widehat{\mathbf{x}}_{l k}^{(i)}$ is the value in $\widehat{\mathbf{x}}_{k}^{(i)}$ corresponding to the latent states.

The estimation of the observation and its covariance together with the cross covariance of $\mathbf{x}$ and $\mathbf{y}$ are computed as follows: 


$$
\begin{aligned}
\widehat{\mathbf{y}}_{k} & =\frac{1}{2 n} \sum_{i=1}^{2 n} \widehat{\mathbf{y}}_{k}^{(i)}, \\
\mathbf{P}_{y}^{-} & =\frac{1}{2 n} \sum_{i=1}^{2 n}\left(\widehat{\mathbf{y}}_{k}^{(i)}-\widehat{\mathbf{y}}_{k}\right)\left(\widehat{\mathbf{y}}_{k}^{(i)}-\widehat{\mathbf{y}}_{k}\right)^{T}+\mathbf{R}_{k}, \\
\mathbf{P}_{x y} & =\frac{1}{2 n} \sum_{i=1}^{2 n}\left(\widehat{\mathbf{x}}_{k}^{(i)}-\widehat{\mathbf{x}}_{k}^{-}\right)\left(\widehat{\mathbf{y}}_{k}^{(i)}-\widehat{\mathbf{y}}_{k}\right)^{T} .
\end{aligned}
$$

Compute the Kalman gain matrix:

$$
\begin{aligned}
& \widehat{\mathbf{x}}_{k}^{+}=\widehat{\mathbf{x}}_{k}^{-}+\mathbf{K}_{k}\left(\mathbf{y}_{k}-\widehat{\mathbf{y}}_{k}\right), \\
& \mathbf{P}_{k}^{+}=\mathbf{P}_{k}^{-}-\mathbf{K}_{k} \mathbf{P}_{y} \mathbf{K}_{k}^{T} .
\end{aligned}
$$

Continue to the $k+1$-th step.

$\widehat{\mathbf{x}}_{k}^{+}$is the states and parameters estimation in the $k$-th step, and $\mathbf{P}_{k}^{+}$is its covariance.

\section{Data Availability}

No data were used to support this study.

\section{Conflicts of Interest}

The authors declare that they have no conflicts of interest.

\section{Acknowledgments}

This work was supported in part by the National Science Foundation of China under Award Nos. 51678116 and 51378093.

\section{References}

[1] B. F. Spencer Jr. and S. Nagarajaiah, "State of the art of structural control," Journal of Structural Engineering, vol. 129, no. 7, pp. 845-856, 2003.

[2] B. Basu, O. S. Bursi, F. Casciati et al., "A european association for the control of structures joint perspective: recent studies in civil structural control across Europe," Structural Control and Health Monitoring, vol. 21, no. 12, pp. 1414-1436, 2014.

[3] F. Casciati, J. Rodellar, and U. Yildirim, "Active and semiactive control of structures-theory and applications: a review of recent advances," Journal of Intelligent Material Systems and Structures, vol. 23, no. 11, pp. 1181-1195, 2012.

[4] G. Wang, S. Veeramani, and N. M. Wereley, "Analysis of sandwich plates with isotropic face plates and a viscoelastic core," Journal of Vibration and Acoustics, vol. 122, no. 3, pp. 305-312, 2000.

[5] Y. Zhou, X. Lu, D. Weng, and R. Zhang, "A practical design method for reinforced concrete structures with viscous dampers," Engineering Structures, vol. 39, pp. 187-198, 2012.

[6] Q. Xue, J. Zhang, J. He, and C. Zhang, "Control performance and robustness of pounding tuned mass damper for vibration reduction in SDOF structure," Shock and Vibration, vol. 2016, Article ID 8021690, 15 pages, 2016.

[7] W. Wang, X. Hua, X. Wang, Z. Chen, and G. Song, "Numerical modeling and experimental study on a novel pounding tuned mass damper," Journal of Vibration and Control, vol. 24, no. 17, pp. 4023-4036, 2017.
[8] L. Tian, K. Rong, P. Zhang, and Y. Liu, "Vibration control of a power transmission tower with pounding tuned mass damper under multi-component seismic excitations," Applied Sciences, vol. 7, no. 5, p. 477, 2017.

[9] W. Fu, C. Zhang, L. Sun et al., "Experimental investigation of a base isolation system incorporating MR dampers with the high-order single step control algorithm," Applied Sciences, vol. 7, no. 4, p. 344, 2017.

[10] Z. Lu, D. Wang, and Y. Zhou, "Experimental parametric study on wind-induced vibration control of particle tuned mass damper on a benchmark high-rise building," The Structural Design of Tall and Special Buildings, vol. 26, no. 8, article e1359, 2017.

[11] Z. Huang, X. G. Hua, Z. Q. Chen, and H. W. Niu, "Modeling, testing, and validation of an eddy current damper for structural vibration control," Journal of Aerospace Engineering, vol. 31, no. 5, article 04018063, 2018.

[12] Z. Wang, Z. Chen, H. Gao, and H. Wang, "Development of a self-powered magnetorheological damper system for cable vibration control," Applied Sciences, vol. 8, no. 1, p. 118, 2018.

[13] J. Ye and L. Xu, "Member discrete element method for static and dynamic responses analysis of steel frames with semirigid joints," Applied Sciences, vol. 7, no. 7, p. 714, 2017.

[14] S. J. Dyke, B. F. Spencer, M. K. Sain, and J. D. Carlson, "Seismic response reduction using magnetorheological dampers," IFAC Proceedings Volumes, vol. 29, no. 1, pp. 5530-5535, 1996.

[15] B. F. Spencer Jr., S. J. Dyke, M. K. Sain, and J. D. Carlson, "Phenomenological model for magnetorheological dampers," Journal of Engineering Mechanics, vol. 123, no. 3, pp. 230-238, 1997.

[16] N. M. Kwok, Q. P. Ha, M. T. Nguyen, J. Li, and B. Samali, "Bouc-Wen model parameter identification for a MR fluid damper using computationally efficient GA," ISA Transactions, vol. 46, no. 2, pp. 167-179, 2007.

[17] A. Al-Hussein and A. Haldar, "Structural health assessment at a local level using minimum information," Engineering Structures, vol. 88, pp. 100-110, 2015.

[18] L. D’Alfonso, W. Lucia, P. Muraca, and P. Pugliese, "Mobile robot localization via EKF and UKF: a comparison based on real data," Robotics and Autonomous Systems, vol. 74, pp. 122-127, 2015.

[19] H. Gurung and A. Banerjee, "Self-Sensing shape memory alloy wire actuator based on unscented kalman filter," Sensors and Actuators A: Physical, vol. 251, pp. 258-265, 2016.

[20] J. S. Lee, I. Y. Choi, S. Kim, and D. S. Moon, "Kinematic modeling of a track geometry using an unscented Kalman filter," Measurement, vol. 94, pp. 707-716, 2016.

[21] H. A. Izadi, Y. Zhang, and B. W. Gordon, "Fault tolerant model predictive control of quad-rotor helicopters with actuator fault estimation," IFAC Proceedings Volumes, vol. 44, no. 1, pp. 6343-6348, 2011.

[22] A. Rahideh and M. H. Shaheed, "Constrained output feedback model predictive control for nonlinear systems," Control Engineering Practice, vol. 20, no. 4, pp. 431-443, 2012.

[23] A. Mirzaee and K. Salahshoor, "Fault diagnosis and accommodation of nonlinear systems based on multiple-model adaptive unscented Kalman filter and switched MPC and $\mathrm{H}$-infinity loop-shaping controller," Journal of Process Control, vol. 22, no. 3, pp. 626-634, 2012.

[24] M. S. Miah, E. N. Chatzi, and F. Weber, "Semi-active control for vibration mitigation of structural systems incorporating uncertainties," Smart Materials and Structures, vol. 24, no. 5, article 055016, 2015. 
[25] B. Allotta, A. Caiti, L. Chisci et al., "An unscented Kalman filter based navigation algorithm for autonomous underwater vehicles," Mechatronics, vol. 39, pp. 185-195, 2016.

[26] R. J. Caverly and J. R. Forbes, "State estimator design for a single degree of freedom cable-actuated system," Journal of the Franklin Institute, vol. 353, no. 18, pp. 4845-4869, 2016.

[27] S. Ramadurai, S. N. Kosari, H. H. King, H. J. Chizeck, and B. Hannaford, "Application of unscented kalman filter to a cable driven surgical robot: a simulation study," in Proceedings of the 2012 IEEE International Conference on Robotics and Automation (ICRA), IEEE, St. Paul, MN, USA, May 2012.

[28] H. Aschemann and T. Meinlschmidt, "Cascaded nonlinear control of a duocopter with disturbance compensation by an unscented kalman filter," IFAC-PapersOnLine, vol. 48, no. 1, pp. 904-909, 2015.

[29] L. Li, G. Song, and J. Ou, "Adaptive fuzzy sliding mode based active vibration control of a smart beam with mass uncertainty," Structural Control and Health Monitoring, vol. 18, no. 1, pp. 40-52, 2011.

[30] M. Singla, L.-S. Shieh, G. Song, L. Xie, and Y. Zhang, “A new optimal sliding mode controller design using scalar sign function," ISA Transactions, vol. 53, no. 2, pp. 267-279, 2014.

[31] M. Heydari, H. Salarieh, and M. Behzad, "Stochastic chaos synchronization using unscented Kalman-Bucy filter and sliding mode control," Mathematics and Computers in Simulation, vol. 81, no. 9, pp. 1770-1784, 2011.

[32] M. Parsapour, S. RayatDoost, and H. Taghirad, "Position based sliding mode control for visual servoing system," in Proceedings of the 2013 First RSI/ISM International Conference on Robotics and Mechatronics (ICRoM), IEEE, Tehran, Iran, February 2013.

[33] L. Li and H. Liang, "Semiactive control of structural nonlinear vibration considering the MR damper model," Journal of Aerospace Engineering, vol. 31, no. 6, article 04018095, 2018.

[34] R. L. Wang, S. C. Ho, and N. Ma, "Active model reference vibration control of a flexible beam with surface-bonded PZT sensor and actuator," Journal of Vibroengineering, vol. 18, no. 1, 2016.

[35] R. Agarwala, S. Ozcelik, and M. Faruqi, "Active vibration control of a multi-degree-of-freedom structure by the use of direct model reference adaptive control," in Proceedings of the 2000 American Control Conference, IEEE, Chicago, IL, USA, June 2000.

[36] H. Gu and G. Song, "Active vibration suppression of a flexible beam with piezoceramic patches using robust model reference control," Smart Materials and Structures, vol. 16, no. 4, pp. 1453-1459, 2007.

[37] G. Song and R. Mukherjee, "A comparative study of conventional nonsmooth time-invariant and smooth timevarying robust compensators," IEEE Transactions on Control Systems Technology, vol. 6, no. 4, pp. 571-576, 1998.

[38] G. Song, R. Mukherjee, G. Song, and R. W. Longman, "Integrated sliding-mode adaptive-robust control," IEEE Proceedings-Control Theory and Applications, vol. 146, no. 4, pp. 341-347, 1999.

[39] H. Gu, G. Song, and H. Malki, "Chattering-free fuzzy adaptive robust sliding-mode vibration control of a smart flexible beam," Smart Materials and Structures, vol. 17, no. 3, article 035007, 2008.

[40] C. Li and B. Cao, "Hybrid active tuned mass dampers for structures under the ground acceleration," Structural Control and Health Monitoring, vol. 22, no. 4, pp. 757-773, 2015.

[41] M. Soleymani and M. Khodadadi, "Adaptive fuzzy controller for active tuned mass damper of a benchmark tall building subjected to seismic and wind loads," The Structural Design of Tall and Special Buildings, vol. 23, no. 10, pp. 781-800, 2014.

[42] Y. C. He and Q. Li, "Dynamic responses of a 492-m-high tall building with active tuned mass damping system during a typhoon," Structural Control and Health Monitoring, vol. 21, no. 5, pp. 705-720, 2013.

[43] N. D. Anh, H.-L. Bui, N.-L. Vu, and D.-T. Tran, "Application of hedge algebra-based fuzzy controller to active control of a structure against earthquake," Structural Control and Health Monitoring, vol. 20, no. 4, pp. 483-495, 2013.

[44] Y. Ikeda, "An active mass damper designed using ARX models of a building structure," Earthquake Engineering \& Structural Dynamics, vol. 45, no. 13, pp. 2185-2205, 2016.

[45] J. Tu, X. Lin, B. Tu, J. Xu, and D. Tan, "Simulation and experimental tests on active mass damper control system based on model reference adaptive control algorithm," Journal of Sound and Vibration, vol. 333, no. 20, pp. 4826-4842, 2014.

[46] L. Li, G. Song, and J. Ou, "Hybrid active mass damper (AMD) vibration suppression of nonlinear high-rise structure using fuzzy logic control algorithm under earthquake excitations," Structural Control and Health Monitoring, vol. 18, no. 6, pp. 698-709, 2011.

[47] H.-C. Tsai and G.-C. Lin, "Optimum tuned-mass dampers for minimizing steady-state response of support-excited and damped systems," Earthquake Engineering \& Structural Dynamics, vol. 22, no. 11, pp. 957-973, 1993.

[48] R. Xu and Ü. Özgüner, "Sliding mode control of a class of underactuated systems," Automatica, vol. 44, no. 1, pp. 233241,2008 .

[49] L. Li, G. Song, and J. Ou, "Nonlinear structural vibration suppression using dynamic neural network observer and adaptive fuzzy sliding mode control," Journal of Vibration and Control, vol. 16, no. 10, pp. 1503-1526, 2010. 


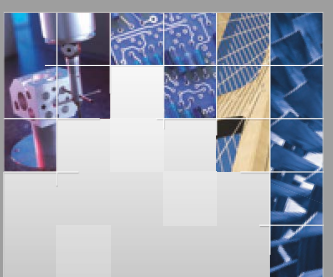

\section{Enfincering}
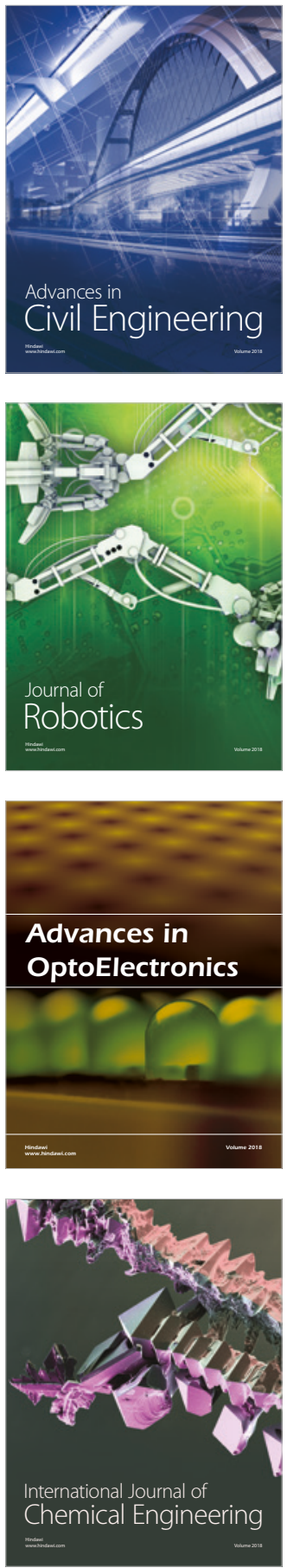

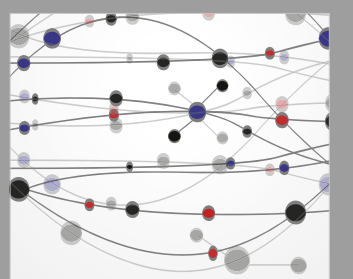

\section{Rotating \\ Machinery}

The Scientific World Journal

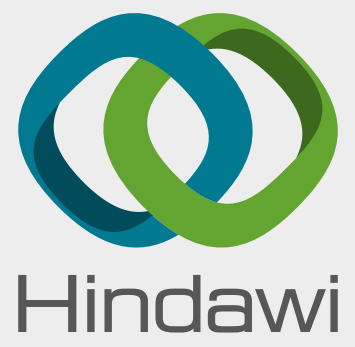

Submit your manuscripts at

www.hindawi.com
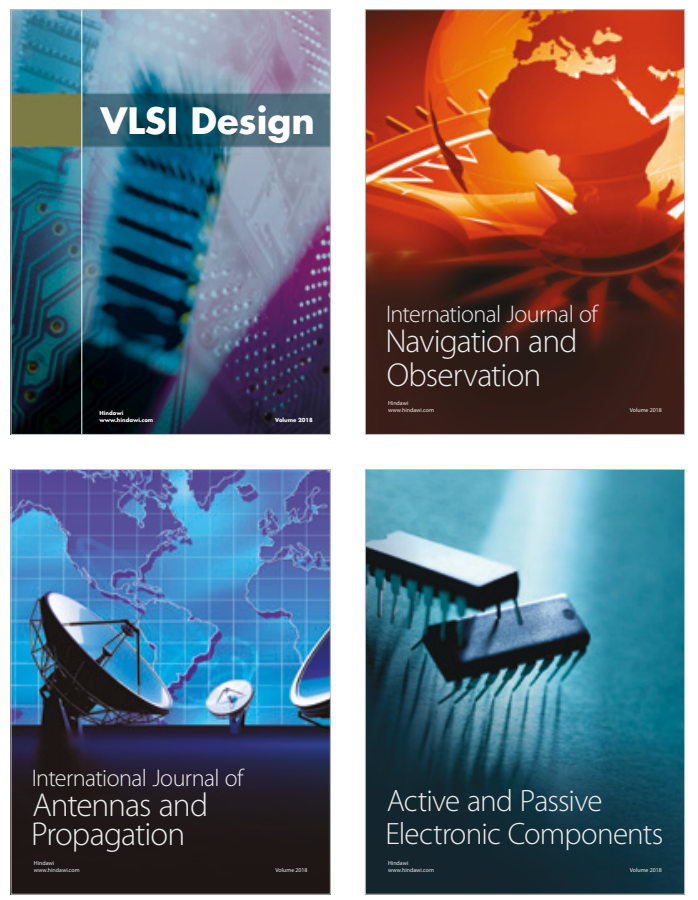
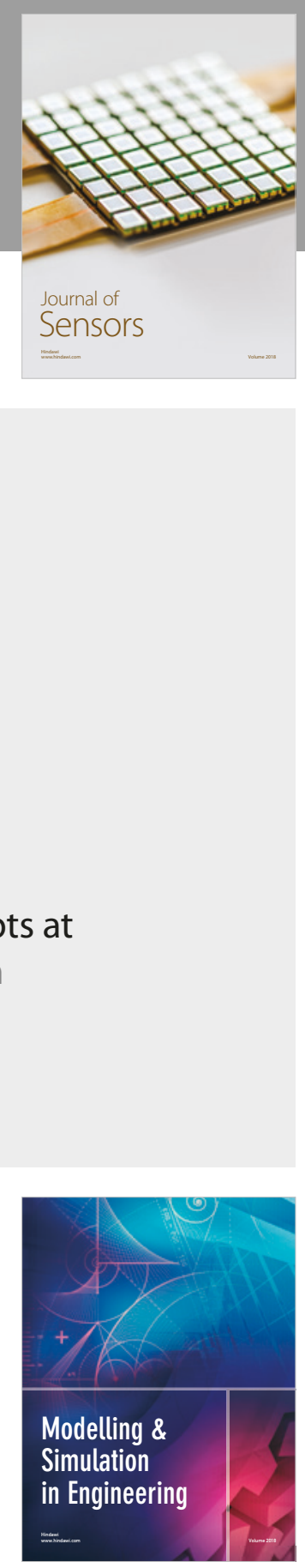

\section{Advances \\ Multimedia}
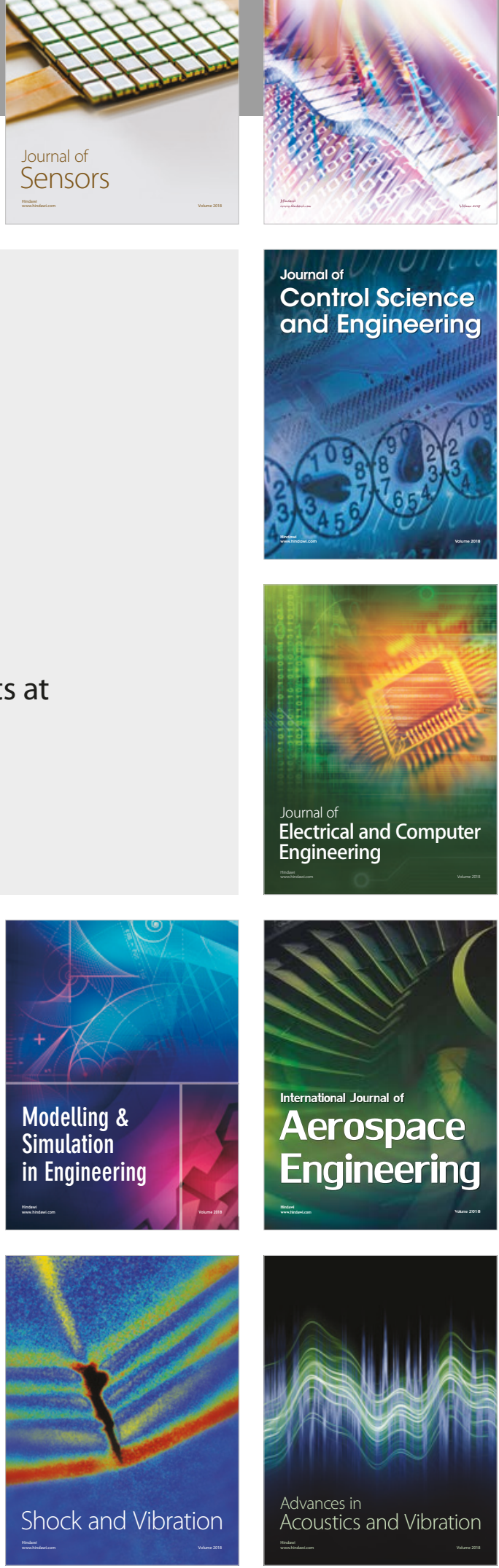